\title{
CONCERNING THE CROCKER LAND EXPEDITION
}

\author{
By C. B. Warner, D. D. S., Committee, Urbana, Illinois
}

( N THE fifth of last July there sailed from Boston the good ship "Diana" bound for the polar regions, and carrying with it a party of scientists, who are to explore the last unknown tract of land in the world. Crocker Land lies adjoining the North Pole, and is of so great scientific interest that this expedition will take three years in making the exploration. The work is undertaken under the auspices of The American Museum of Natural History, The American Geographical Society, and The University of Illinois.

This expedition is of particular interest to the members of the dental profession, for on that boat was a full dental equipment for the use of the men while in the North. Best of all, it was loaned by the National Dental Association. For the first time in history, a national scientific body has met on equal terms and received assistance from a dental organization. For the first time in history, a devoted body of scientists will have their teeth attended to without the usual extractions while engaged in work in the remote parts of the world.

The dental equipment will be in charge of the physician of the party, who has had instruction in this line of work. The Lee Smith \& Son company aided us with a donation. We are under deep obligation to the S. S. White Company, not only for a donation, but also for their aid in the selection of the equipment and placing it on board the vessel.

This was partly reported at the Kansas City meeting, but since that time your committee has received word from the expedition since their arrival at Etah, North Greenland. We learn that they are safely installed in their winter headquarters. They had found two of the Peary guides-Kakochingwo and Koodlooktoo-and twenty-six other Esquimaux, eighty dogs, and twenty-five pups. Altogether it looks like business. As many in this party were with Peary, there is little doubt but that the expedition will be a success. The extensive literature received from Etah makes very interesting reading. One wishes he were there (if it were not so cold) but as space forbids an extensive report, I will i'eproduce an Etah postal, which will be the last message we will receive for a year, as the passage beyond the Arctic Circle is now closed.

We all wish to thank you for the nice dental equipment with which you supplied us. We are established in Etah, having been kept from crossing to Ellesmerland by the pack ice which has not broken out this year. It does not alter our plans materially, however.
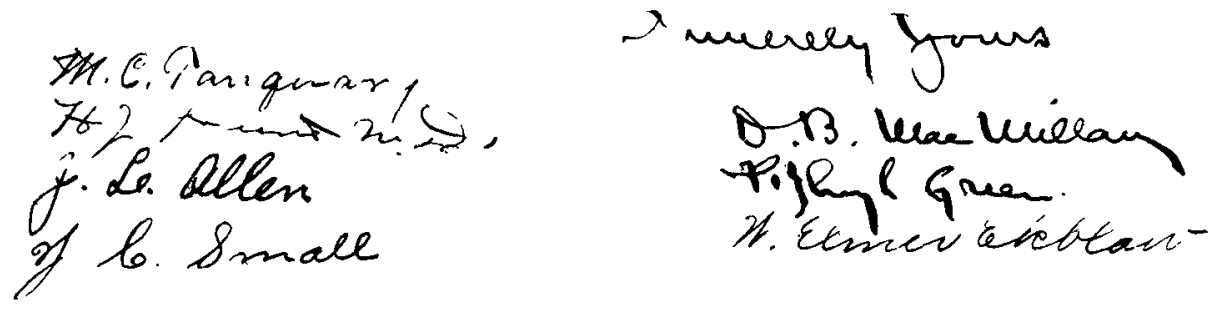